\title{
DIE PROBLEMATIEK VAN VOLKSWORDING IN AFRIKA
}

Die groeiende proses van ontvoogding van Afrika het plaasgevind met die klem op bepaalde gebiede: Ghana, Nigerië, Kenia e.d.m. Die mense van die gebiede het op die agtergrond van die kenniswêreld en van die bewussyn gebly. Hiervoor moet waarskynlik twee veroorsakende faktore verantwoordelik gehou word. Die een is 'n erfenis uit die koloniale tydperk. Dit was kenmerkend van die stormloop na Afrika dat die belanghebbende koloniseerders „kleims" afgepen het. Hulle het letterlik beslag gelê op territoriaal-administratiewe eenhede en het dienooreenkomstig grense bepaal waarby die organiese, histories-geworde etniese eenhede weinig of geensins in ag geneem is nie.

Die tweede verklarende faktor is waarskynlik die feit dat die ontvoogdende koloniale moondhede na die Tweede Wêreldoorlog, hoewel begaan oor humaniteit en menseregte onder die druk van ander veral, nog nie ontdaan was van die ou siening nie, terwyl juis die volksgedagte totaal ongewild was by die gangbare wêreldmening. Die menslike faktor kan dus alleen begripmatig weergegee word deur na die gebied te verwys wat deur hulle bewoon is.

Wat in die kalklig verskyn, wat die hooflyne van die pers en die beriggewing van die radio gehaal het, was derhalwe die nuwe state wat nou tot stand gekom het en wel op die grondslag van die territoriaal-administratiewe eenhede wat ongeveer ' $n$ eeu gelede deur die koloniseerders uit Afrika uitgekerf is.

Die slagspreuk "verdeel en heers" is tradisioneel geassosieer met koloniale bewind en imperialisme. In werklikheid is dit slegs een kant van die saak. Dit is veral waar vir sover die koloniseerder in sy inwendige beheer veelal probeer het om te voorkom dat die samestellende eenhede van 'n onderhorige gebied kragte saamsnoer tot 'n georganiseerde eenheidsfront teen sy gesag. Een van die bekende metodes hiertoe was om die leiers oor te haal na die kamp van die regerende deur prestige-posisies, persoonlike voordeel, intimidasie e.d.m., en 'n tweede om agterdog en wantroue te wek tussen die groepe onderling.

Die ander verdelingsaksie van die koloniserende het veelal, ook in Afrika, daarin bestaan dat die nuwe maghebber om 
praktiese en strategiese redes en dikwels sonder enige besondere rede, uit onkunde grense vasgestel het wat dwarsdeur historiese en organiese eenhede soos stamme, volke, taalgroepe, statte e.d.m. gesny het.

Die ander kant van die saak is tog ook dat die koloniserende mag, dikwels nieteenstaande sy eie optrede en beleid, miskien bloot ter wille van administratiewe gerief, juis as verenigende mag opgetree het. Die mees klassieke voorbeelde hiervan is Engeland se administrasie van die eertydse veelvuldigheid van Indiese state en ryke en vorstedomme, waaruit twee groot en getalsterke state gegroei het teen die tyd toe Brittanje sy mag teruggetrek het. Eweneens het Indonesië sy staatkundige eenheid eintlik te danke aan die administratiewe bindmag van die vroeëre Nederlandse administrasie en bewind.

In die tweede fase van die ontvoogding van die Afrikagebiede is die oë weliswaar skerper gerig op die menslike aspek. Nou was die algemene idioom: nasiebou. Pres. Kenyatta het die dubbele strewe saamgevat in die leuse: Vryheid en eenheid. Om aan die nuut ontstane staat wat nou ontdaan was van die eksterne saambinding deur die koloniale mag, 'n binding van binne uit te verskaf, om die dikwels uiteenlopende stameenhede en die reeds ontstamdes plus die etniesen rasvreemde immigrantegroepe te sementeer, is en word getrag om die aandag te vestig op die pogings tot vereniging van mense en lojaliteite om die én faktor van die staat of die leier. Dit mag een van die faktore wees wat gelei het tot die besondere posisie van die leier as verpersoonliking van die staat.

Erken of verloën, die ondergrond van die strewe tot nasiebou was die onmiskenbare simptoom van die universeel-historiese verskynsel van, ten minste die begeerte na, volkswording of volkwees. Van die een kant gesien is dit die behoefte om aan die staat ' $n$ organiese eenheidsgrondslag in die gestalte van die kultureel, histories en psigologiese eenheid, nl. die volk te gee. Andersyds: dat die volk sy politieke vergestalting in 'n staat probeer vind. Die opvallende is dat die gang hier van die periferie af na die sentrum gestimuleer word en nie 'n groeiproses van die middelpunt af na die omtrek is nie. Die kunsmatige, rasionele en selfs gedwonge gerigtheid staan sterker op die voorgrond as die organiese, natuurlike proses wat geleidelik deur verstand en beleid in ordelike bane gelel word.

Op die ingeslane weg was en is die probleme velerlei. 
Allereers is daar die intellektueel-psigologiese vraagstuk van die verbreding van die denke en siening van 'n stamsentriese na 'n nasie- of staatsentriese politieke benadering. Die politieke siening moes verbreed word - 'n proses wat nooit te gemaklik is nie - in die aanwesigheid van allerlei belemmerende faktore.

'n Ander aspek van die historiese faktor, dikwels ononderskeibaar van die genoemde seksionele lojaliteite ten koste van ' $n$ eenheidsvisie en lojaliteit, is die bestaan van ou vetes, negatiewe onderlinge waardering, werklike of gewaande bedreiging van gevestigde groepsbelange e.d.m. Daar moet veel vergewe en vergeet word; daar moet nuwe onderlinge waardering van mekaar kom voordat die primêre lojaliteit teenoor die kleinere groep verbreed word tot die grotere. Die hele lewenshouding moet eintlik omgekeer word. Voorheen is die fokus gerig op die stam of ander seksionele eenheid met die etniese of die nasionale vaag in die omtrek en teen die agtergrond - soms selfs in die gedaante van ' $n$ bedreigende monster. Die nuwe vereis 'n fokus op die omtrekke van die nasie en die staat met ' $n$ vervagende of vervaagde bewussyn van die verskeidenhede daarbinne.

- Albei prosesse is tydsaam. Met die koloniserende en van buite saamhoudende mag nou uit die prentjie en die nodige van binne uit saambindende krag nog slegs 'n droom, word dit nog moeiliker om 'n staat te bestuur en 'n politieke samelewing te ontwikkel. Diegene aan die stuur moet eintlik 'n wonderbaarlike mengsel van bomenslik-wyse staatmanskap en van politieke gimnastiek beoefen om behoue die oorkant te haal. Ons stelling is nie dat volkseenheid per se 'n stabiele en wyse regering waarborg nie, maar wel dat die vervanging daarvan met heterogene en botsende komponente die regeringstaak nog moeiliker maak.

'n Groot aantal staatswrakke en 'n ewe groot aantal moeilik varende staatskepe in Afrika getuig van hierdie problematiek. Allerlei middele word aangewend om te kan bestaan en voort te gaan: beklemtoning van staatsprestige, leierstatus, dwang, politieke truks e.d.m. Brittanje se beleid ten opsigte van Kenia, Zambië en veral Rhodesië is daarvan getuie. Die V.V.O. en sy ondersteuners se beleid m.b.t. S.W.A. spreek dieselfde taal net soos die wêreldmening oor Suid-Afrika dieselfde grondtoon openbaar.

Uiteraard wortel dié beleid en optrede in die denkrigting 
van die hele huidige wêreld. Die rasionalistiese sosiologiese gedagte van 'n wêreldsamelewing omspan deur 'n wêreldstaat, die beklemtoning van die mensheid ontdaan van verskeidenhede, eenheid deur eenvormigheid i.p.v. deur eensgesindheid, resulteer in die sfeer van die politieke denke in die opvatting dat elke staat as onderdeel van 'n eventuele wêreldstaat, 'n mikroskosmos moet wees. Die staat, groot of klein, sou van bó en van buite af die bindmiddel van die heterogene nasie wees.

In hierdie denke - meer emosioneel en ideologies as realisties - word baie dinge uit die oog verloor en die mens meesal, onbewus miskien, aanvaar as 'n maklik plooibare suiwere rasionele wese wat primêr deur sy gesonde rede gelei word. Dit lê ten gronde van die wêreldbenadering oor S.W.A. Dat die Herero histories nie te vinde is vir 'n stelsel waarin Nama of Ovambo oor hom sal regeer nie is vir hierdie denke of onbelangrik of totaal onbekend. Dieselfde geld die houding van Herero en Nama m.b.t. die Damaragroep. In Nigerië het die veelgeroemde federale staat as „model demokrasie" in Afrika in duie gestort omdat die samestellende etniese en godsdienstige komponente wantrouend teenoor mekaar staan. 'n Britse gesag van buite kon hulle saamhou; 'n Nigeriese gesag is onder omstandighede nie daartoe in staat nie. Uganda beleef iets soortgelyks ten opsigte van Buganda en die Kabaka. Die poging om Blank en Bantoe in Rhodesië tot 'n ontydige eenheid saam te dwing teen alle wense en begeertes in, het reeds gelei tot 'n wêreldinsident.

Waar Amerika die ywerige apostel van die "great society"gedagte is, is dit interessant om te merk hoe die Amerikaanse „image" op Afrika geprojekteer word. Die V.S.A. is immers éen groot staat met territoriaal, ekonomies, kultureel en politiek ingeskakelde gefedereerde state. Die bevolkings verkeer vrylik(?) met mekaar en daar is gesamentlike optrede. Sonder enige diepgaande analitiese en historiese besef of etnologiessosiologiese realisme word hierdie beeld - in sy veridealiseerde perspektief - sonder wysiging of aanpassing geprojekteer op Afrika. Afrika word, in dié siening, 'n territoriaal- en kultureel-sosiologiese eenheidskonsepsie en Africans die parallel van Americans. Derhalwe bestaan daar in die politieke denke van die Amerikaanse beleidmakers geen problematiek nie. Gerieflik is vergeet dat die V.S.A. basies 'n Wes-Europese bevolkingsagtergrond het, dat „vreemdes" soos die Negers 
nog nie vreedsaam geakkommodeer of bevredigend geassimileer is nie en dat die binnekoms van 'n sterk Asiatiese element in die weste van dié land met ' $n$ aansienlike mate van politieke, kulturele en sedelike desorganisasie gepaard gaan.

Om ' $n$ verskil in hierdie verband raak te sien moet die aandag gevestig word op die R.S.A. Die Republiek is, volgens die wêreldmening en sommige van sy eie inwoners, uit pas met die res. Waarop word hierdie oordeel gebaseer? In die eerste plek seker op die koers wat Suid-Afrika inslaan en wat sterk histories verklaarbaar is, nl. die klem op die volkse of etniese. Die huidige bewindhebbers het die pad van die volkstryd geloop. Hierin is die begrip van Afrikanerskap vooropgestel. $\mathrm{Na}$ twee kante is dit beklemtoon en beleef: teenoor die Engelssprekende maghebbers en mededingers en teenoor die getalsterkere, opkomende, hoewel nog nie maghebbende Bantoes en ander nie-blankes.

'n Interessante proses is tans besig om hom hier te voltrek en een wat in sekere opsigte ' $n$ teenstrydigheid bevat. Die onderskeiding (blanke) Afrikaner vs. Bantoe plus nie-blanke is tot dusver hoofsaaklik as 'n rasse-onderskeiding verklaar en benader. Hoeveel misverstand en ellende dit vir ons veroorsaak het, kan moeilik bereken word. Deur skade en skande en deur nadere analitiese betragting is ons tans besig om die rassiese op die agtergrond te skuif en die konsep van etniese onderskeiding na vore te bring. Die kombersterm Bantoe met die ooreenstemmende veralgemeende Bantoebeleid, maak stadigaan plek vir die etnies onderskeidende terme van Zoeloe, Xhosa, Tswana en ander volkseenhede met hopelik ook meer aandag aan die implikasies daarvan vir die beleid en administrasie.

Tog is daar vandag ook duidelik 'n tendens te bespeur wat eintlik strydig is met hierdie een en wel in die sfeer van die Afrikaner-Engelse verhouding. In 1952 en weer in 1960 is die leuse geformuleer: ons bou 'n nasie. Afrikanerskap, vrug van die etniese denke word terug gedu in die pers, die ekonomiese realiteite, die politiek e.d.m. deur die breëre nasiekonsep veral in die sin van aanvaarding van 'n gemeenskaplike staatslojaliteit en patriotisme deur Afrikaans- en Engelssprekende Suid-Afrikaner. In dié verband is die term Suid-Afrikaner betekenisvol.

Geheel en al in verband met die besef van die bedreiging deur die nie-blankes se getalle, hetsy as ras-eenheid of volkere- 
verskeidenheid of as albei gesien, het 'n derde begrip op die voorgrond getree wat eintlik teen die verloop in is, hoe verklaarbaar ook al. Die begrip blankedom ding vandag om voorrang mee met die ou bekende konsepte van Afrikanervolkskap en Suid-Afrikaanse nasieskap. Hiermee is ons wesentlik terug by die rasse-onderskeiding en beklemtoning waarvoor slegs twee getuienisse aangehaal hoef te word: die wetgewing ten opsigte van die Kleurlinge en die immigrasiebeleid.

In hierdie verband lewer die R.S.A. ' $n$ illustrasie van die ganse problematiek. Geheel in stryd met die volstruispolitiek van die wêreld, het Suid-Afrika tot kern van sy beleid geneem die volkekundige vraagstuk van etnogenese, die geboorte en groei van volke. Soos hierbo aangestip het ons weliswaar uit die kors van die tradisionele en uit die labirint van politieke oorwegings en gevestigde belange nog nie volkome daarin geslaag om 'n onbevange en heldere blik op die besonderhede van die situasie te kry nie. Die beweging is nogtans, miskien voel-voel en struikel-struikel en selfs in halwe sirkels in die één koers: om geleenthede te skep vir en 'n proses te bevorder van saamgroeiing van etnies en kultuur verwante eenhede tot volke en hulle onderskeiding van ander minder verwante eenhede; die erkenning en ontwikkeling van ' $n$ bepaalde gebied as tuisland en vaderland in daardie etniese eenheid en die uitbou van politiek-administratiewe apparaat as staat of politieke vergestalting van elke volk.

Hierdie beleid berus op die uitgangspunt van die volkstaat as ideale politieke ordening, omdat dit die natuurlike gesagsvorm van die volk is met die minimum van konflikpunte en strydvlakke. Hieraan het die wêreld 'n broertjie dood vanweë die heersende opvatting dat nasionalisme of etnosentrisme die sentimente om die volksbestaan - die groeibodem van alle euwels en boosheid is. (Vgl. Jan Rabie: Die Evolusie van Nasionalisme). In die praktyk geld dit uiteraard altyd die nasionalisme en volksliefde van ander. Op hierdie gebied staan die V.S.A. se binnelandse en buitelandse beleid nie 'n haarbreedte terug by dié van Rusland, China, Frankryk en S.A. vir sover dit etnosentries gemotiveerd is nie.

Sodanige uitgangspunt vereis opnuut weer 'n duidelike antwoord op en herwaardering van die verhouding van volk, nasie en staat en ' $n$ noukeurige analise van die volksbegrip, wat selfs in die Volkekunde grootliks uit die gesigsveld gestoot is. Die volk, moet ons onthou, is 'n eenheid. Maar prinsipieel 
is dit ' $n$ ope eenheid hoewel nie perkeloos en vormloos oop nie. Daarin is anwesig die werking van middelpuntsoekende en middelpuntvliedende kragte, van „fission and fusion"; aanvaarding en weiering. Terselfdertyd is dit 'n eenheid wat interne verskeidenheid omvat en geen dooie eenselwigheid veronderstel nie, hoewel die verskeidenheid ook sy perke het.

Met die volk as prinsipieel ope en verskeidenheidseenheid word verwys na die feit dat dit anders as 'n ras "vreemde" toevoeginge kan ontvang sonder om noodwendig of prinsipieel, behalwe wat sy biologiese samestelling betref, sy identiteit te verloor. 'n Volk kan verander sonder verlies van identiteit; ' $n$ ras nie. Want juis die essense van 'n volk se onderskeidende bestaan, sy kultuur, is onderhewig aan gedurige wysiging hetsy van buite of van binne. Maar die wysiginge, hetsy in biologiese samestelling, hetsy in kultuurpatroon, hetsy in historisiteit, is nie onbeperk nie. Alle innovasies, biologies of kultureel, van buite of binne staan voor 'n poort met twee grendels: om te aanvaar en om aanvaar te word. Nuwelinge, immigrante, mag bereid wees om die volk waarby hulle hulle voeg te aanvaar terwyl daardie volk vanweë sekere vreemdhede, vertolkinge, waarderinge, nie bereid is om hulle te aanvaar nie, of omgekeerd. Oor wat aanvaar sal word, is moeilik te profeteer omdat ons hier met 'n komplekse motivering te doen het. Tog is dit nie onmoontlik om met kennis van bepaalde omstandighede voorspellinge te waag en selfs op enkele algemene neiginge, moontlikhede en waarskynlikhede te wys nie.

'n Gemeenskaplike vaderland, liefde vir 'n bepaalde landgebied, ook genoem patriotisme, kan bv. 'n baie sterk bindingsfaktor wees selfs tot so ' $n$ mate dat dit uiteenlopende elemente tot 'n volk kan help saamsnoer en -bind. Hierdie element word meesal sterk beklemtoon. Wie saamwoon is geneig om saam te groei en moet ten minste een of ander akkommodasiepatroon vind, al is dit in die etniese gelaagdheid van die Hima-Iru of die Hutu-Tutsi. Maar die rol van die grond is afhanklik van ander en nog kragtiger faktore. As elemente $\mathrm{X}$ en $\mathrm{Y}$ wat op dieselfde grondgebied of in aangrensende gebiede woon, begeer om een te word, of negatief gestel, geen beswaar voel om tot een te vergroei nie, dra die gemeenskaplike patriotisme, die eenheid in woongebied onteenseglik veel by tot die etniese vergroeiing op biologiese, kulturele en politieke gebiede.

Aan die ander kant kan liefde vir dieselfde gebied van 
onderskeie etniese eenhede wat deur historiese gebeure territoriaal gemeng of in noue buurskap woon, juis 'n onoorkomelike struikelblok vorm op die pad na volkskap en juis die strydfaktor word indien die betrokke elemente beswaar het teen eenwording. Suid-Afrika se geskiedenis van Boer vs. Brit, blanke vs. nie-blanke, Duitsland en Frankryk oor die Saar, en talle ander voorbeelde spreek duidelike taal hieroor. In daardie dele van Afrika waar blankes en ander nuwe immigrante (Asiate in Oos-Afrika bv.) gevestig geraak het aan die grond, was die wrywing die felste, terwyl in Wes-Afrika waar blankes hoogstens amptenare en handelaars was maar geen boerende koloniste nie, die ontvoogding die maklikste verloop het.

Getalle speel ook ' $n$ rol. Dit is opmerklik dat indiwiduele vreemdelinge, nuwelinge wat geen groep vorm nie vanweë hulle geringe getalle en gevolglike verspreiding oor die etniese eenheid waaronder hulle hulle bevind makliker geassimileer word. Wanneer vreemdelinge ' $n$ bepaalde getalsverhouding die optimum is nog nooit vasgestel nie - bereik, word die vreemdheid makliker as bedreiging ervaar en word opname moeiliker. Dit is die situasie van Asiatiese en blanke minderhede oral in Afrika. Dit hang natuurlik ook daarmee saam dat die immigrantegroepe dan self enige assimilasie kan begin teenstaan.

Oor 'n gemeenskaplike taal as bindingsmiddel, as bevorderaar van volkskap kan daar geen verskil bestaan nie. Deur jou land met ander te deel kan jy jouself in gevaar stel; deur jou taal met ander te deel word jy alleen maar net sterker. Omgekeerd is taalverskille 'n sterk negatiewe element: dit identifiseer die vreemdeling, die onvolkse. Dit is veral kragtig as daarmee ander skeidingsfaktore soos ou vyandskappe en bedreiginge geassosieer word. (Vlaams- en Waalssprekende Belge, Afrikaans- en Engelssprekende Suid-Afrikaners). In Afrika is dit uiters belangrik. Met die verspreiding van etlike honderde tale en dialekte oor 'n 60-tal potensiële volke, kry haas elke (wordende) volk, in elke geval elke staat te doen met die kwessie van 'n taalverskeidenheid en met die praktiese aktualiteit: watter een is die landstaal? Hoe moet opgetree word om nie aanstoot te gee aan die verskillende taalgroepe nie? Dit mag prakties wees om één omgangstaal as kommunikasiemiddel te hê, maar dan liefs 'n neutrale of vreemde soos Frans of Engels of Swahili of Fanakalô eerder as die taal van een besondere groep wat aanstoot aan ander kan gee. Dit is opmerklik 
hoe die inboorlingtaal in die nuwe state na vore skuif, soos die onderrig in Setswana in Botswana. Hierin lê 'n simptoom van herwaardering van die volkseie en dus van die ontwakende volkskap.

Die religie is ook 'n faktor wat nie buite rekening gelaat mag word nie. Eén nasionale godsdiens, is 'n bindende faktor van onberekenbare krag. Dit geld in Afrika soos in die geval van die meeste primitiewe volke waarin die kultuur deur en deur religieus georiënteerd is en die sekularisasieproses eintlik weinig gevorder het, in die besonder. Islam en Animisme in een staat, bly ' $n$ bron van botsing soos dit in die geval van die Soedan en van Nigerië besonder duidelik getoon is. Historiesetnologies gesien het die koms van die Christendom tot dusver ook veelal gedien as 'n skeidende faktor waar die hele volk nog nie gekersten is nie en word die stryd tussen Christendom, Islam en Animisme dikwels op die volk oorgedra. Die sekulariseringsproses met 'n quasi-Christendom mag 'n obstruksie word op die weg van volksgroei in baie Afrikagebiede.

Opvoeding, in die breë sin van die woord, en beskawing speel 'n wisselende rol veral omdat dit gekoppel is aan die omvang van die etniese horison. 'n Hoë algemene ontwikkelingspeil neig daartoe om die horison te verbreed en 'n laer peil om dit te vereng. Dieselfde opvoedingsinhoud en vlak kan grootliks help om saam te bind, maar groot opvoedingsverskille tussen onderskeie etniese eenhede wat weerspieël word in beskawingsverskille is ' $n$ skerp skeidingsfaktor. Dit moet gesien word teen die agtergrond van die verskynsel dat by 'n hoër opvoedingsvlak die rasionele of verstandelike faktor as regulerende en motiverende sterker op die voorgrond kom, terwyl by die meer primitiewe die emosionele en tradisioneel bepaalde gevoelspatroon die deurslag gee.

Afrika bevat, in stryd met die beeld wat blykbaar by baie bestaan, deureenvermengd in die verskillende gebiedstate en nie net naasmekaar wonend in etnies-gebaseerde politieke eenhede nie, 'n groot aantal verskeidenhede wat vir die etnogenese 'n obstruksie vorm. Die gebruik van die term African wis dié verskille net so min uit as die benaminge Asiaat, Europeaan of Amerikaan die inwoners van hierdie kontinente reduseer tot eenselwige bevolkings. Alhoewel die naam geassosieer word met sg. swart volke, is almal nie eers Negers of Negroïde nie, maar het Afrika reeds die tuiste geword van volke en volkskomponente van Europese, Asiatiese, Hamitiese en Semi- 
tiese oorsprong plus die Khoisan en 'n nuwe komponent, die Kleurling. Naas hierdie raskundig-biologiese verskille is daar uiteenlopend gefundeerde of gewortelde kulture en beskouings: Europees-tegnologies-Christendomlik georiënteerd; Oosters-religieus-kommersieel; Islamities, religieus bepaald; Negroied-landboukundig, sedentêr en matrilinies gebaseerde sowel as Hamitiese, pastorale en nomadiese groepe. Om komponente van meer as een hiervan in 'n staatsgemeenskap te akkommodeer en te laat saamgroei tot 'n eenheidskultuur en 'n volk, is geen geringe taak nie.

Van besondere betekenis vir die etnogenese is die geskiedenis. Enersyds oorwegend skrifloos en andersyds alleen in enkele gevalle werklik volke, bestaan daar in Afrika weinig volksgeskiedenis. In suidelike Afrika het slegs Tsjaka, Moshoeshoe en Umswati enigsins daarin geslaag om uit stamgroepe en stamme 'n volk binne één nasie- en staatsgemeenskap saam te snoer. Hoogstens sou ons Mzilikazi se werk, nl. om uit een Ngunistam deur dwanginlywing van Sotho-elemente, ' $n$ volk te bou, kon noem. Maar vandag bestaan die Ndêbêlê (Matebêlê) nouliks nog as volk en het dit weinig vooruitsig op eie nasieskap en vaderland. Ander voorbeelde is te vinde in Egipte, Ethiopië en in ander Noord-Afrika-gebiede. Alleen Egipte en Ethiopië het 'n werklik ou volksgeskiedenis en daarby een wat die volkstrots op grond van oeroue voorvaderlike prestasies kan aanwakker. Die ander Noord-Afrikaanse volke(?) se geskiedenis dateer van die sewende eeu, d.w.s. van die Islamities-Arabiese verowering af. Dié van die suidelike volke is nouliks 'n eeu oud.

Vir die volksbewussyn is 'n besef van historiese verbondenheid en van toekoms-gemeenskaplikheid wat daaruit opspruit van buitengewone belang. Wat daar aan geskiedenis bestaan op enkele uitsonderinge ná - is legende en mite. Elke volk is geneigd om sy geskiedenis te vermitologiseer: dit is hierdie, meesal verheerlikte en veridealiseerde "goue verlede" wat psigologies ' $n$ volkstimulus is, nie die wetenskaplike en kritiese geskiedenis wat die volle waarheid oor volksprestasie en mislukking oopkrap en blootlê nie. 'n Volk leef bewus uit sy geskiedenis soos hy dit wil onthou. Onder die Bantoes gewaar ek ' $n$ interessante verskynsel - een wat nie totaal onbekend in die Westerse (en Oosterse) wêreld is nie, nl. van geskiedenis ontkenning. Dit geld waarskynlik hoofsaaklik van die geletterdes. Hulle kennismaking met en aanvaarding van Westerse 
beskawingstandaarde wek blykbaar 'n skaamte oor hulle geskiedenis uit die tyd voor die koms van die blanke en selfs gedurende die eerste kontakfase. Hulle wil dit nie aanvaar as hulle geskiedenis nie. Daarby het die jongere geslagte deur die verval van die stamskole al minder bekend geword met die stamgeskiedenis. Dan is daar ook diegene wat doelbewus die veridealiseerde vermitologisering van die Bantoeverlede ter hand geneem het soos Mutwa e.a. Hierdie ontwaking tot die besef van ' $n$ eie volksgeskiedenis is ' $n$ belangrike simptoom in die verskynsel van etnogenese, maar of die betrokke voorbeeld in die doel slaag, is ' $n$ ope vraag.

Hoe moeilik hierdie vraagstuk word, kan gesien word wanneer ons let op die feit dat deur die toedoen van die koloniale tydperk die meeste state vandag bevolkinge omspan bestaande uit allerlei etniese komponente wat nog één kultuur, nog één godsdiens, nog één geskiedenis het. Hiervan noem ek enkele as besondere voorbeelde: Nigerië, Kenia, Tanzanië, Zambië, Algerië, Kongo, Angola, Mosambiek, Soedan, Uganda, Rhodesië, S.W.A. (en die R.S.A. soos die wêreld hom wil sien).

Hierdie feit beklemtoon twee aspekte. Enersyds is etniese eenhede hierdeur politiek, ekonomies en andersins versnipper soos in die geval van die Tswana, die Swazi's, die Ovambo, die Masai, die Somalis met die Nilote van Noord-Sentraal-Afri$\mathrm{ka}$ as 'n klassieke voorbeeld, naamlik verdeel onder die Soedan, Sentraal-Afrikaanse Republiek, Uganda, Kongo en Kenia. Die een kant verteenwoordig dus die uiteenhou van saamhorige komponente. Die ander openbaar die vraagstuk van die saamvoeging van nie-saamhorige eenhede. Om 'n staatspatroon op etniese basis in Afrika te rekonstrueer sal baie veranderinge en herreëlings van grense en state vereis. Eers sal dit „depart"-heid vereis om tot by apartheid te kom (Mosaka). In hierdie opsig is partisie 'n aktuele beleidsvraagstuk soos in die R.S.A., Rhodesië, Nigerië ens. Maar eweneens vereis dit nuwe samevoegings soos in Somalië, die Nilote, Togo, ens. Hierdie situasie is waarskynlik een van die mees gekompliseerde erfenisse uit die Europese stormloop van Afrika en die afpen van koloniale kleims.

In die oë van die wêreld is dit 'n onbegonne taak en 'n dwase ideaal. Die wedervraag is of dit nie makliker sal wees nie om dié ideaal te bereik, en profytliker met ' $n$ veel bestendiger en ryker uitkoms as om te ywer vir die saamgroei van heterogene en veelal strydige rasse-, kulturele-, beskawings-, 
taal- en historiese elemente tot 'n 'homogene staatsgemeenskap waarin die meeste oorsake vir konflik en onenigheid ondervang sal wees.

'n Nadere aanduiding van enkele gevalle mag die probleme enigsins meer konkreet in perspektief stel. Algerië, die Kongo, Kenia, Tanzanië, Zambië, Rhodesië en Suid-Afrika, in besondere sin ook Angola en Mosambiek, illustreer die vraagstuk van rasse- en beskawingsverskille in dieselfde staat. M.i. was die rasseverskil aanvanklik sekondêr m.b.t. die beskawingsandersheid maar oral is die verskil in lewenswyse en -waardes, gefokus en geprojekteer op en gefundeer in die sigbare somatiese verskille. Hierdie kompleks het tot dusver nog 'n onoorkoomlike hindernis tot nasie- en volkseenheid gevorm en selfs aanleiding gegee tot ernstige konflik. Die aansprake van Kenia, Zambië en Tanzanië op die geslaagdheid van die proefneming met veelrassige nasieskap ten spyt, is daar geen werklike eenwording nie. Daar is hoogstens 'n gekunstelde vrede, enigsins aangehelp deur die kleiner wordende minderheid van blankes. Tekens van wrywing met die Asiatiese groep in Kenia en Tanzanië is orals te lees.

Lande soos Nigerië, Kongo, Kenia, Tanzanië, die Soedan bevat ook ' $n$ ander kompleks van skeidende faktore. Die raskundige is enigsins minder opvallend maar dié gebaseer op uiteenlopende inheemse kulture soos herders, landbouers en handelaars, patri- of matriliniêre verwantskapsberekening, Islam en Animisme, taal- en stamaffiniteite laat hulle deeglik geld. Nigerië kan nieteenstaande die poging tot saambinding deur die Britse administrasie met behulp van 'n Westministerkonstitusie, die invloed van werklik belangrike en bekwame staatsliede, die staatkundige eenheid teen die druk van etnies onverwante eenhede nie bewaar of herstel nie.

In Angola en Mosambiek is Portugal eintlik, meer in lyn met die wêreldmening as met Suid-Afrika, besig met die tweeledige doelstelling om blank en Bantoe te verenig tot gemeenskaplike Angolese en Mosambiekse komponente van die Portugese volk. Dit is 'n gedugte taak. Gedagtig aan wat in Brazilië en elders in Suid-Afrika gebeur het, moet toegegee word dat assimilasie tussen Bantoe en Portugees in hierdie twee provinsies makliker kan gebeur as in die lande hierbo genoem. Die geskiedenis leer ons dat die Suid-Europese volke makliker die rasgrens oorsteek as die Noord-Europeërs.

Die finale doel staan onder 'n skerp vraagteken. Weer 
in die lig van die geskiedenis van Brazilië en van die Portugese beleid om vanweë sterk militêr-strategiese en ekonomiese motiewe, groter getalle soldate-nedersetters uit te stuur, is dit meer as ' $n$ blote moontlikheid dat 'n nuwe patriotisme mag ontstaan wat die grondslag sal vorm van Mosambiekse en Angolese nasies en volke, los van Portugal soos Brazilië vroeër of soos Amerika in die geval van Engeland in die verlede... en Rhodesië in die nabye toekoms?

Veral in daardie gebiede waar die vestiging van blankes en die toedoen van ander faktore die beskawingsontwikkeling van die inboorlingvolke van Afrika besonder gestimuleer het, het ook 'n nuwe hindernis in die weg van die volksgroei ontstaan. Hier is veral ter sprake die sosio-ekonomiese differensiasie met alles wat daaromheen geskaar kan word. Dit sluit die groter of kleiner groep in wat deur die blanke se opvoedingsmiddele iets opgedoen het uit die Westerse beskawing. Maar wyer as hierdie kern moet ook ingesluit word die groter groep wat regstreeks of onregstreeks uit hulle stammilieu gelok of gedwing is na die nuwe bestaansentra: na boerderye en nywerhede, na dorpe en stede. Afgesien daarvan dat hulle met nuwe en voorheen onbekende bestaanswyses kennis gemaak en daardeur van die ekonomies-bepaalde patroon van hulle tradisionele kultuur losgeraak het, het nuwe beroepsgroepe en klasse ontstaan. Meesal was dit 'n geval van ruimtelike en kulturele verwydering van die bekende en tradisionele. Die eerste generasie het nog die opvoeding as band besit; die tweede het dit onregstreeks, sonder eie belewing, van die ouers ontvang; die derde is wesentlik vreemdelinge met geen ander eie kennis van vaderland, kultuur en lewenswyse as dié van die omgewing waarin hy gebore en getoë is nie.

Dit het gebruik geword om na hierdie proses en toestand te verwys met terme soos ontstamming, denasionalisering, verstedeliking en verwestering. Die korrekte en presiese inhoud hiervan is nie altyd omskryf nie. Ondersoek toon aan dat dié woorde nie noodwendig sinonieme is nie. Mense kan ontstam sonder om te denasionaliseer; hulle kan uiterlik verstedelik sonder om te ontstam; hulle kan verwesters sonder om hulle volkskap af te sweer. Nogtans bly die feit dat dit 'n ontwikkeling verteenwoordig wat verwydering van die tradisionele bevorder en 'n saamgroei tot volkskap erg kan belemmer. Liberië sit vandag met die probleem van skeiding tussen die Kreole (nakomelinge van die vrygesette slawe) en die inheemse be- 
volking van die gebied. Die gewese Franse gebiede het lank te worstel gehad met die elite wat hulle heil gesoek het in die strewe na inskakeling by die Franse volk. In die R.S.A. is een van die aktueelste probleme van afsonderlike volksontwikkeling, die herstel van 'n eenheidsbewussyn en -strewe tussen die verstedeliktes en die tuislanders. Hier moet 'n sintese gevind word tussen die oue en die nuwe wat vir almal heilsaam sal wees.

15 Maart 1967.

J. H. Coetzee. 